\title{
ESTADO, MOVIMENTOS E REFORMA AGRÁRIA NO BRASIL: REFLEXÕES A PARTIR DO INCRA*
}

\author{
Camila Penna \\ Universidade de Brasília (UnB),Brasilia.DF-Brasil.<marcelocrosa@gmail.com> \\ Marcelo C. Rosa \\ Universidade de Brasilia (UnB), Brasília,DF - Brasil.<marcelocrosa@gmail.com> \\ http://dx.doi.org/10.1590/ 0102-6445057-085/95
}

A história das mobilizações por terra no Brasil contemporâneo tem sido trabalhada por diversos autores e autoras que tendem a enfatizar primordialmente dois polos: (i) as formas de organização coletiva das populações rurais em movimentos como: Movimento dos Trabalhadores Rurais Sem Terra (MST), Confederação Nacional dos Trabalhadores na Agricultura (Contag), Ligas Camponesas, entre tantos outros (Carter, 2010; Deere, 2003; Martins, 2000); e (ii) os processos de oportunidades políticas que se abriram em determinados governos ou contextos, como a ditadura e a abertura política (Wolford, 2010; Sabourin, 2008). Entre uma abordagem e outra, surge a pergunta sobre como as demandas por terra, os aparatos legais e as políticas públicas que surgiram nesses contextos são elaborados, processados e redistribuídos para sem-terras, trabalhadores rurais e populações tradicionais na forma de programas de assentamento, extensão rural, educação e comercialização, por exemplo.

\footnotetext{
* Este artigo é produto de pesquisas realizadas pelo Laboratório de Sociologia Não Exemplar (<www.naoexemplar.com>) e foi financiado com recursos da Capes e do CNPq.
} 
Na busca de uma descrição mais acurada desses processos, nosso foco aqui se dará na principal agência estatal encarregada de lidar com a questão da terra no Brasil, o Incra (Instituto Nacional de Colonização e Reforma Agrária). É quase sempre com o Incra (e não por meio do Incra) que sem-terras, quilombolas e outros grupos têm acessado tanto a terra como seus possíveis benefícios e problemas. Longe dos estereótipos clássicos da burocracia de Estado consagrados pelas ciências sociais, de um Estado autárquico ou mesmo fraco (Wolford, 2010), o Incra tem sido, ao longo dos últimos quarenta anos, um dos órgãos mais sensíveis às transformações políticas no Brasil, tanto em termos de suas ações quanto da composição de seus quadros funcionais.

Neste artigo, defenderemos a ideia de que no Brasil, especialmente nas duas últimas décadas, o processo de constituição do aparato estatal voltado para a reforma agrária 58 caminha pari passu com as mobilizações por terra e, por conseguinte, com a instituição de políticas públicas. Argumentamos também que as políticas públicas para as áreas rurais são constituídas, transformadas e aplicadas em múltiplos níveis, desde os gabinetes dos ministérios até os assentamentos de reforma agrária. Nesse sentido, não se poderia trabalhar com a noção já clássica de que a interação e a transformação das políticas se dá apenas no momento de sua implementação, quando o Estado encontra seus "clientes" na ponta final do processo burocrático (Lipsky, 1980).

Por ser alvo de disputas e controvérsias constantes, defendemos a noção de que nesse processo não há actantes estabilizados e consistentes com funções demarcadas e definitivas, ou seja, não existem um Estado, um movimento ou um beneficiário isolados (Law, 2004) ${ }^{1}$. É nossa intenção

\footnotetext{
1 Neste artigo, utilizamos a noção de actante em diálogo com Latour (2005), para demarcar objetos cujos efeitos podem ser visualizados e traçados em nossas pesquisas.
} 
assinalar que é pela permeabilidade e constante negociação desses burocratas ou servidores com vários atores em diferentes níveis que o Estado, de forma heterogênea, se faz fundamental na vida das populações em áreas rurais brasileiras que reivindicam terra ${ }^{2}$.

No decorrer do texto, procuraremos apontar os problemas centrais levantados pela bibliografia que busca compreender as relações entre Estado e movimentos olhando para os processos de formulação e execução de políticas públicas, demonstrando alguns de seus limites a partir de dois casos. O primeiro é a incorporação na pauta dos movimentos (especialmente MST e Contag) da reivindicação por concursos públicos e aumento de verbas para o Incra (mostrando como a pauta dos movimentos se move). O segundo são as negociações para a formulação e execução de políticas de assistência técnica para assentamentos de reforma agrária.

Os dois casos foram pesquisados separadamente e em momentos distintos por cada um dos pesquisadores, empregando as mesmas técnicas de pesquisa. Realizamos observações etnográficas nas superintendências regionais de Recife, capital de Pernambuco (entre 2001 e 2004), e em Marabá, município do Pará (de 2011 a 2013). Mesmo tendo sido realizadas em tempos e com objetivos diferentes, as observações construídas nos chamaram a atenção para certos limites da literatura e da pesquisa empírica e, ao mesmo tempo, sugerem pistas para uma agenda futura de estudos sobre movimentos sociais rurais e Estado no Brasil contemporâneo.

2 Mello (2012) buscou analisar a relação entre Incra, movimentos sociais e beneficiários usando casos ocorridos em duas superintendências no Sul e no Nordeste do Brasil. Amarrado pela visão teórica normativa dos estudos clássicos de brokerage, seu estudo não consegue ir além da denúncia de certas relações específicas de privilégio dentro do Instituto sem, no entanto, avançar na compreensão de suas implicações teóricas para as ciências sociais. 


\section{Incra: uma breve apresentação}

Criado em 1970, pelo Decreto-lei no 1.110 , o Incra é uma autarquia que veio substituir e assumir as atribuições de duas instituições então existentes: o Ibra (Instituto Brasileiro de Reforma Agrária) e o INDA (Instituto Nacional de Desenvolvimento Agrário). Um dos objetivos do governo militar com a unificação dos dois órgãos - que tinham, respectivamente, as funções de promover a reforma agrária e de desenvolver o setor rural - era avançar no projeto de colonização da região amazônica.

No escopo desse projeto do governo, que estava associado também à intenção de neutralizar conflitos por terra nas regiões Nordeste e Sul do país, o Estado investiu recursos e contratou pessoal para trabalhar no Incra. Com a redemocratização, o projeto ambicioso de colonização foi deixado de lado, e o órgão passou a se dedicar à sua função de executor da reforma agrária, agora com recursos escassos e 60 reduzida prioridade. Na década de 1990, em grande medida como resposta à mobilização dos movimentos sem-terras, o Incra começa a trabalhar mais intensamente na desapropriação de áreas e na criação e gestão de projetos de assentamento rural. Desde 2003, o Instituto passou também a ser o responsável por políticas de reconhecimento e titulação das terras ocupadas por quilombolas. A partir desse mesmo ano, são realizados diversos concursos para o órgão, e a força de trabalho duplicou entre 2003 e 2012. Nessa nova fase, alguns estudos como o de Penna (2013) assinalam que militantes de movimentos têm prestado concurso público para trabalhar no órgão, passando a desempenhar suas funções burocráticas e de direção.

Atualmente, o Incra é uma autarquia vinculada ao Ministério de Desenvolvimento Agrário (MDA) e tem uma força de trabalho de aproximadamente 6 mil servidores. É um órgão da administração pública federal, descentralizado em todos os estados da federação. Além da sede em Brasília, 
existem trinta Superintendências Regionais (SR) do Incra espalhadas pelo território nacional, as quais têm autonomia relativa - podendo indicar o nome do superintendente e definir a lotação dos servidores locais. Em estados com forte conflito agrário, como Pará e Pernambuco, há mais de uma $\mathrm{SR}^{3}$. Superintendências localizadas em regiões com grande extensão territorial contam ainda com as Unidades Avançadas, órgãos de execução descentralizados, de caráter transitório, e subordinados às SRs. Existem atualmente 45 Unidades Avançadas.

\section{Um breve mapa do debate sobre movimentos sociais, burocracia, Estado e políticas públicas}

Partindo de diferentes enfoques teóricos, os estudiosos de movimentos sociais têm cada vez mais se dedicado à compreensão da relação entre movimentos e Estado e seus efeitos sobre a produção de políticas públicas (Goldstone, 2003; Mische, 2008; Abers e Keck, 2006; Abers e Von Bulow, 2011; Silva e Oliveira, 2011).

Paralelamente, tem havido um esforço por parte dos pesquisadores que se dedicam ao tema da burocracia no sentido de compreender como ela se relaciona com o campo mais amplo da política partidária (Praça, Freitas e Hoepers, 2011; Lopez, Bugarin e Bugarin, 2013) e com a sociedade civil organizada (Souza e Pires, 2013). No campo da implementação de políticas públicas, os estudos sobre burocracia de nível de rua (street-level bureaucracy) têm buscado compreender como burocratas que trabalham na linha de frente influenciam o formato final das políticas (Lipsky, 1980; Maynard-Moody e Muscheno, 2003; Lotta, 2010).

O caso do Incra nos coloca diante do desafio de trabalhar com uma realidade empírica em que todas as relações

3 O Estado do Pará tem três SRs: SR 01 (Belém), SR 27 (Marabá) e SR 30 (Santarém). E o Estado de Pernambuco tem duas: SR 03 (Recife) e SR 29 (Petrolina). 
que vêm sendo tratadas separadamente pela literatura citada aparecem sobrepostas. No Incra, os clientes são organizados em movimentos sociais, que participam do processo de formulação e de implementação de políticas públicas. Os burocratas do órgão, do nível de rua ao mais alto escalão, se relacionam diretamente com lideranças desses movimentos. Além disso, o Incra é uma autarquia pouco insulada, e altamente permeável à interferência político-partidária, o que está relacionado ao ponto anterior. Vale lembrar que as lideranças dos movimentos que organizam os beneficiários estão conectadas aos partidos políticos, em laços que perpassam o Incra e o transbordam.

A realidade empírica observada no Incra - que se repete em outros órgãos nos quais movimentos e organizações que representam beneficiários interagem com partidos e servidores de carreira na produção de política públicas nos coloca ante o desafio de desenvolver ferramentas teóri62 cas capazes de produzir explicações que façam jus à riqueza dos objetos de pesquisa. No caso específico trabalhado neste artigo, a análise deve dar conta de trazer para a mesma explicação atores e relações que têm sido trabalhados separadamente pela literatura, mas que se encontram sobrepostos no Incra. Para tanto, revisitamos a seguir algumas das contribuições que olham para diferentes facetas das relações entre movimentos sociais, Estado, partidos políticos, burocracia e clientes.

Pela diversidade de formatos de interação entre Estado e movimentos sociais - tributária tanto do histórico de mobilização da sociedade civil em diferentes esferas, quanto das características específicas da burocracia estatal em cada setor de políticas públicas -, o caso brasileiro contribui para tencionar os modelos teóricos construídos a partir de experiências empíricas ocidentais (Silva e Oliveira, 2011).

Diferentemente do contexto que caracterizou o período de transição democrática, a relação entre movimentos 
e Estado no Brasil tem sido marcada, na última década, por uma relação de colaboração, que, por vezes, envolve o "trânsito institucional" de militantes pelos órgãos estatais (Silva e Oliveira, 2011). Estudos empíricos que sustentam o argumento da relevância dessa estratégia de atuação institucional para os movimentos sociais a partir de 2003 indicam a necessidade de superar as tradições teóricas que privilegiam a dimensão do conflito ou que enfatizam a divisão entre Estado e sociedade civil (Abers e Von Bulow, 2011).

Buscando sistematizar diferentes experiências de participação na era Lula, Abers, Serafim e Tatagiba (2014) se inspiram no conceito de repertórios de Tilly (2006) para criar uma tipologia das rotinas de interação Estado-movimentos. As autoras identificam quatro repertórios de interação: protestos e ação direta (que podem ser concomitantes a processos de negociação); participação institucionalizada (em conselhos, conferências e outras arenas de participação); política de proximidade (fundamentada em contatos pessoais entre atores do Estado e da sociedade civil); e ocupação de cargos na burocracia. Os repertórios variam conforme a esfera de políticas públicas e os movimentos geralmente adotam uma combinação deles.

No caso das políticas de reforma agrária, o repertório de protesto é utilizado como forma de iniciar e conduzir negociações (Abers, Serafim e Tatagiba, 2014), rotina de interação que já foi internalizada por gestores e servidores de carreira do órgão (Penna, 2013). A partir de 2003, com a chegada do Partido dos Trabalhadores (PT) à direção do Incra, a ocupação de cargos na burocracia também passou a ser um repertório importante para os movimentos de luta pela reforma agrária. Vale lembrar que, ao contrário dos outros três, repertórios de participação institucionalizada nunca foram uma estratégia privilegiada pelos movimentos, nessa esfera, para influenciar políticas de reforma agrária. 
A relação entre Incra e MST na definição de políticas de reforma agrária é interpretada por Wolford (2010) como um lugar de democracia participativa, um espaço que não foi planejado, mas que se construiu na prática devido à falta de prioridade dada à autarquia pelo governo brasileiro e ao concomitante papel ativo do movimento social. Essa situação teria resultado em um processo de participação significativa do movimento na definição de políticas de reforma agrária.

A capacidade que os movimentos sociais têm de influenciar políticas de reforma agrária passa pela compreensão do papel da burocracia e das formas de interação que se estabeleceram ao longo do tempo entre os servidores do Incra e as lideranças de movimentos, atualmente referidas por ambos como "relação de parceria". A atuação do movimento acabou por construir categorias, como "acampamento", "sem-terra" e "movimento", com as quais o Estado tra64 balha (Rosa, 2011; Sigaud, 2005), que foram internalizadas e são atualizadas nas práticas cotidianas dos servidores do Incra (Penna, 2013). Portanto, para compreender de forma adequada a influência dos movimentos sobre políticas públicas, é necessário levar em conta o papel da burocracia e das relações que burocratas estabelecem com os movimentos.

A partir da observação do comportamento de funcionários que atuam na linha de frente da implementação das políticas, Lipsky (1980) concluiu que a burocracia nesse nível tem características específicas que a distinguem de outros setores do Estado. A principal delas é a discricionariedade. Devido às especificidades de suas funções, como, por exemplo, a necessidade de traduzir e aplicar políticas nacionais à realidade local dos clientes, esses burocratas precisam definir rotinas e inventar recursos para lidar com incertezas e imprevistos de seu trabalho, e, ao fazê-lo, "processam clientes" com certo grau de discricionariedade. 
Essa discricionariedade dos burocratas que atuam na linha de frente influencia o formato final da política pública, e, por isso, ela não pode ser entendida olhando-se apenas para os altos gabinetes de gestores. Essas arenas de tomada de decisão são importantes, mas elas não representam o quadro completo. Ao conjunto de lugares onde a política é feita, devem-se adicionar os escritórios dos trabalhadores que estão na ponta e em contato direto com os clientes (Lipsky, 1980).

O argumento de Lipsky (1980) sobre a discricionariedade como característica fundamental do trabalho desses burocratas da linha de frente é sustentado por pesquisas empíricas com trabalhadores em diferentes áreas: agentes do Programa Saúde da Família (Lotta, 2010); policiais (Oliveira, 2012); professores (Maynard-Moody e Musheno, 2003). A disparidade entre as políticas formuladas e o formato final que elas adquirem no momento da implementação - considerando-se o grau de discricionariedade inerente ao trabalho dos burocratas da linha de frente -, e a necessidade de controle desse processo, têm sido alvo de discussão no campo acadêmico e normativo (Pires, 2009).

A interação com os clientes é uma característica fundamental da burocracia de nível de rua, contudo, de acordo com Lipsky (1980), esses clientes não têm poder de barganha na relação com os burocratas, uma vez que geralmente não podem abrir mão dos serviços oferecidos pelo Estado. Dessa forma, não seriam agentes determinantes do comportamento dessa burocracia de linha de frente. O caso da relação entre o Incra e seus clientes não sustenta esse argumento. Os clientes são representados por movimentos sociais, que também se organizam em múltiplos níveis, e que têm um histórico de ações de protesto mescladas com negociações com o Estado. Os servidores do Incra que trabalham na linha de frente da implementação de políticas de reforma agrária interagem com clientes ativos, que negociam 
frequentemente suas demandas por meio de seus representantes imediatos: as associações de assentados que fazem a interface com o Estado.

Movendo-se da noção de que burocratas "processam clientes" passivos em direção a uma interpretação que dá maior agência aos clientes no processo de implementação de políticas, estão os achados de Dubois (2010 [1999]). A pesquisa etnográfica feita pelo autor em uma agência de welfare francesa mostra como são complexos estes "encontros burocráticos”. À medida que implementam políticas, os burocratas reforçam identidades e regras institucionais. Mas, além disso, eles têm diferentes perfis e histórias de vida e, frequentemente, se envolvem pessoalmente com seu trabalho e com os clientes. Estes, por sua vez, podem tanto se adaptar às instituições como fazer as instituições se adaptarem a eles, apontando suas fraquezas e criando dificuldades para o seu funcionamento.

Seguindo na construção do mosaico teórico que pode 66 ajudar na compreensão do caso do Incra, é necessário considerar a atuação dos partidos políticos. Embora existam pesquisas interessantes sobre a relação entre burocracia e partidos (Praça, Freitas e Hoepers, 2011; Lopez, Bugarin e Bugarin, 2013) e sobre a relação entre movimentos e partidos (Silva e Oliveira, 2011; Mische, 2008), ainda não há pouco esforço no sentido de compreender a relação entre movimentos, burocracia e partidos como actantes heterogêneos nesse caso.

Ao analisar os militantes do movimento estudantil brasileiro nos anos de 1990, Mische (2008) observou que eles tinham envolvimentos múltiplos e sobrepostos, que incluíam filiações religiosas, profissionais, estudantis e partidárias. As relações partidárias perpassavam e influenciavam as dinâmicas de quase todos os setores, informando os diálogos e ações políticas entre os diferentes grupos. Naquele contexto, as lideranças tinham importante papel de mediação entre partidos, notadamente o PT, e outras esferas. 
É importante lembrar que no contexto da pesquisa de Mische, o PT tinha como parte importante de sua estratégia a mobilização social, e ainda não tinha conquistado espaços institucionais significativos.

Em um contexto político mais atual, ao estudar a trajetória dos militantes do movimento de economia solidária no Rio Grande do Sul, Silva e Oliveira (2011) concluíram que o PT tinha importante papel de mediador entre Estado e movimento social. O trânsito institucional desses militantes entre a sociedade civil e o Estado, com a ocupação de cargos comissionados, foi mediado por seu pertencimento partidário. Os militantes que ocuparam cargos na burocracia estadual tinham experiência de militância no PT (além da militância no movimento de economia solidária) ou se filiaram ao partido posteriormente. Nos diferentes casos, o partido foi um ator relevante para explicar a atuação dos militantes do Estado.

Os estudos sobre indicações políticas para cargos do Executivo trazem aportes relevantes para a análise do caso do Incra na medida em que contribuem para pensar a relação entre burocracia e política partidária (Borges, 2005). Praça, Freitas e Hoepers (2011) e Lopez, Bugarin e Bugarin (2013) apresentam dados sobre as indicações políticas para cargos do Executivo e argumentam que, em um presidencialismo de coalizão, essas indicações têm o importante papel de garantir a coesão dos aliados na aprovação de matérias no Congresso, além do controle sobre o processo de produção de políticas públicas. Como demonstram Praça, Freitas e Hoepers (2011), o MDA e o Incra são órgãos gerenciados pelo PT e têm um número significativo de cargos de confiança, em comparação com outros órgãos da administração pública federal. Cabe mencionar que, no caso do Incra, muitos dos cargos de livre nomeação são ocupados por militantes do partido que também são servidores de carreira. 
Os impactos dessas indicações sobre a organização dos servidores de carreira e sobre as políticas públicas não são alvo de análise desses autores. Todavia, estes são temas fundamentais para a compreensão das políticas públicas formuladas e implementadas pelo Incra, uma vez que a nomeação de gestores a partir de critérios políticos não é ponto pacífico entre os servidores de carreira e, em alguns casos, causa resistências e controvérsias que têm efeitos sobre seu trabalho cotidiano (Penna, 2013).

Como sugerem Abers e Von Bulow (2011), a abordagem de redes pode ser uma ferramenta interessante para investigar como movimentos sociais influenciam políticas públicas por dentro e por fora do Estado. Essa abordagem é útil porque oferece um panorama geral de como atores se relacionam e de como a configuração dessas relações tem efeitos diferentes nas políticas públicas. O mapeamento das redes permite também contemplar o papel dos burocratas, 68 dos partidos políticos, das lideranças e dos clientes, conforme cada um desses atores aparece como empiricamente relevante no processo de criação das políticas públicas.

Contudo, a fragilidade desse tipo de abordagem é que ela não trabalha profundamente o conteúdo das relações, o que, no caso da pesquisa do Incra, é importante. Como alguns atores são ao mesmo tempo servidores, militantes de partido e ligados a movimentos sociais, mapear suas relações em determinado momento não explica por que eles atuam de diferentes formas, conforme a situação. É importante lembrar que as relações, assim como as filiações, são instáveis e variam de acordo com o contexto. É nesse sentido que a abordagem etnográfica que usamos nas duas pesquisas pode oferecer uma contribuição relevante. $\mathrm{O}$ acompanhamento de atores ao longo do tempo e em situações variadas permite identificar como eles acionam conexões e filiações diferentes, de acordo com o contexto, o que pode ter impactos imprevisíveis para as políticas negociadas e adotadas. 


\section{Conexões em múltiplos níveis de mediação: a parceria}

Como afirmamos anteriormente, os servidores do Incra interagem com movimentos sociais em diferentes níveis, desde as Unidades Avançadas até a sede, em Brasília. A complexidade dessas interações tem, nesse caso, uma característica singular em relação à bibliografia que apresentamos: segundo Moyo e Yeros (2005), o caso brasileiro parece ser um dos únicos do mundo em que são os movimentos que criam e, ao mesmo tempo, organizam a demanda e as listas de beneficiários para o Programa Nacional de Reforma Agrária (PNRA). Associar essa definição simplesmente aos modelos clássicos de reforma agrária popular, como bem lembram os autores, seria, no entanto, desprezar a força mediadora (Latour, 2005) do Estado nessas situações ${ }^{4}$.

Em certo sentido, como já afirmamos em outro lugar (Rosa, 2011), a constituição do Estado no sentido de desapropriar terras e prover alguns serviços básicos nas áreas rurais não dominadas pelo latifúndio a partir dos anos de 1980 é resultado direto da ação de diversos movimentos sociais. Do mesmo modo, a constituição dos movimentos como legítimos representantes de demandantes por terra foi construída com base nas respostas positivas de setores estatais ao longo das últimas décadas, especialmente a partir do anos 1980 (Sigaud, Macedo e Rosa, 2010).

Como o público-alvo das políticas públicas implementadas pelo Incra é feito e representado pelos movimentos, os servidores que trabalham no Instituto, tanto na sede como nas Superintendências e Unidades Avançadas, interagem (de formas nem sempre amistosas, como veremos adiante) com suas lideranças e pessoas assentadas cotidianamente. É essa interação que possibilita a execução das políticas de

\footnotetext{
4 Resumindo argumentos de outros autores, Moyo e Yeros (2005, p. 65) classificam os modelos de reforma agrária do século XX como sendo "de Estado", "de mercado" e "popular".
} 
reforma agrária, desde a obtenção de terras, passando pelo assentamento de famílias, assistência técnica e a transferência de recursos para fomento à produção.

Baseada nas pesquisas de campo mais recentes realizadas em Brasília e na Superintendência de Marabá (SR 27), a Figura 1 permite visualizar o mapa complexo das relações observadas no cotidiano da SR 27, envolvendo servidores do Incra, movimentos, partidos, grupos privados e outros órgãos do Estado.

Apesar de as conexões que produzem as políticas de reforma agrária serem mais amplas, dentro dos limites do debate bibliográfico deste artigo, consideramos na análise apenas as questões relativas aos servidores, movimentos e beneficiários $^{5}$. É importante notar que a representação da Figura 1 não reproduz nenhum esquema formal de relações que se encontra em manuais ou cartilhas. Seguindo nossa proposta analítica, o que temos aqui é o resultado sistema70 tizado da observação de eventos oficiais e informais, entrevistas e consultas a documentos e processos, que nos permitem construir um coletivo de actantes que pode ser observado em Penna (2013). Essa construção se funda justamente nas controvérsias e justificativas elaboradas em momentos específicos, aos quais tivemos acesso nos dois períodos e locais. Especificamente, trabalharemos a seguir dois eventos centrais para formulação de nossas hipóteses.

\section{Definindo um quadro de servidores: acampando por concursos}

É necessário voltar alguns anos para compreender melhor o entramado que envolve hoje o Incra, seus servidores, lideranças de movimentos e beneficiários de programas de reforma agrária, e que forneceu as primeiras pistas do problema da pesquisa.

5 Uma análise mais completa é feita em Penna (2013). 
Camila Penna e Marcelo C. Rosa

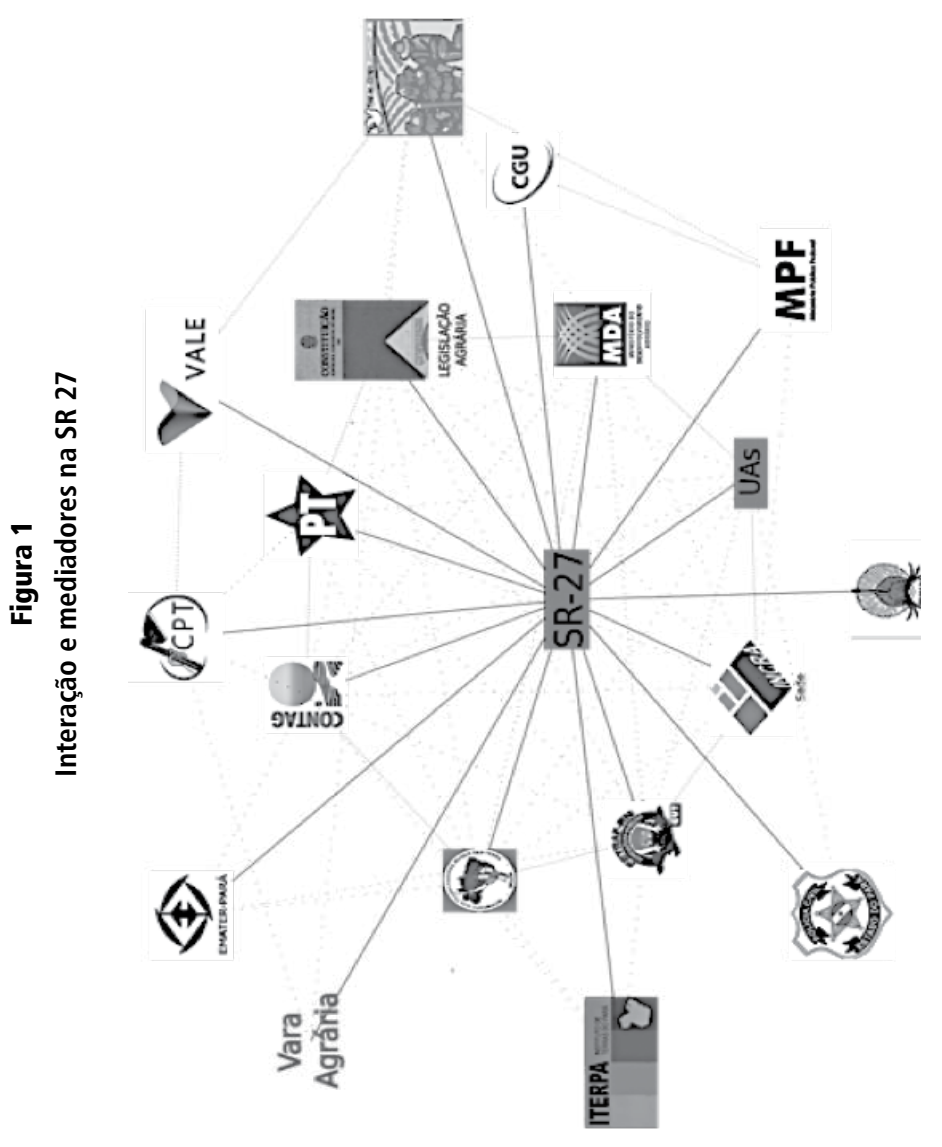


Entre 2001 e 2004, um dos pesquisadores realizou um trabalho de campo no Estado de Pernambuco, na área sob responsabilidade da SR 03, de Recife. Naquele momento, Pernambuco era a região do país com o maior número de acampamentos e ocupações de terra em todo Brasil. Também chamava a atenção o número de movimentos envolvidos tanto na organização das ocupações como nas negociações com o Incra, que passavam de quinze.

Era o período que chamamos de pós-massacre de Eldorado do Carajás ${ }^{6}$, no rastro do qual se criaram e se aprofundaram políticas e medidas do governo Fernando Henrique Cardoso para conter os protestos e ações majoritariamente encabeçadas pelo MST e pelas federações filiadas à Contag. Entre as ações, podemos contabilizar o aprofundamento das políticas de crédito e também de desapropriação de terras e formação de assentamentos rurais ${ }^{7}$.

O crescimento no número de beneficiários e demandas

72 para o Incra nos anos de 1980 e 1990 não foi acompanhado nem por infraestrutura, nem por um quadro de funcionários condizente com o volume de trabalho. Como destacamos em Rosa (2011), especialmente nos anos de 1990, as ocupações e acampamentos na sede da SR 03 se tornaram constantes e complementares às ocupações de fazendas improdutivas. Se a ocupação de terras designava o local no

\footnotetext{
6 Evento ocorrido no dia 17 de abril de 1996, no qual a polícia do Pará assassinou dezenove membros do MST que organizavam o bloqueio da rodovia PA-150, em área sob jurisdição da SR 27.

7 Até 1996, existiam 163.372 famílias assentadas pelo Incra. Entre 1997 e 2004, foram assentadas mais 554.303 famílias. Ou seja, entre 1996 e 2004, o número de famílias em assentamentos sob responsabilidade do Incra subiu de 163.372 para 718.275. O número de decretos desapropriatórios também aumentou após o massacre de Eldorado dos Carajás. Até 1996, já haviam sido desapropriadas 2.062 propriedades rurais no Brasil (o processo de desapropriação é um processo administrativo conduzido pelo Incra e formalizado por decreto presidencial). Entre 1997 e 2004, foram desapropriadas mais 3.344 propriedades para fins de reforma agrária. O número de Projetos de Assentamento subiu de 1.788, em 1996, para 5.986, em 2004. Fonte: Incra. Disponível em <http://www.incra.gov.br/reforma-agraria/ questao-agraria/reforma-agraria>. Acesso em: $1 \mathrm{dez} .2014$.
} 
qual o Estado deveria agir (Sigaud, 2005), as ocupações do Incra indicavam as lacunas existentes na própria estrutura do Estado, as quais dificultavam a implementação de assentamentos e outras políticas ligadas à reforma agrária.

Nos primeiros acampamentos realizados no governo Fernando Henrique Cardoso, observavam-se pautas e ações sempre ligadas às necessidades dos sem-terras e dos movimentos (desapropriação, créditos e, em geral, substituição do superintendente). No ano de 2003, logo após a nomeação do primeiro Superintende Regional pelo governo Lula (um militante do PT com afinidades com os movimentos de luta pela terra), além das demandas por assentamento e políticas voltadas para os assentamentos rurais, sugiram na pauta das ocupações reivindicações para o fortalecimento institucional do próprio Incra. Nessas mobilizações, além de serem solicitados mais recursos que beneficiassem diretamente os assentados e acampados, solicitavam-se também maiores investimentos do governo federal na administração do órgão. Ademais, nesse mesmo período, sugiram nas pautas das ocupações de Pernambuco e de outros estados do país as reivindicações por concursos públicos ${ }^{8}$.

A entrada nas pautas de reivindicação da questão dos concursos unia mobilizações de alguns movimentos (MST e Contag, principalmente) com as reivindicações dos órgãos de classe de funcionários do Incra, especialmente CNASI, Assera e Assincra ${ }^{9}$, criando conexões estratégicas ${ }^{10}$. As rei-

8 Em 2004, um superintende regional do Incra, ao pedir demissão, declarou publicamente: "De 325 funcionários que atuavam na década de 90 no estado, restaram atualmente 68 . Número dramaticamente insuficiente ante a demanda crescente nos assentamentos e que dificulta a execução das tarefas atribuídas ao Incra". Fonte: Folha de S.Paulo on-line, 30 abr. 2004. Disponível em: <http://www1. folha.uol.com.br/folha/brasil/ult96u60507.shtml>. Acesso em: 17 nov. 2014.

9 Respectivamente: Confederação Nacional das Associações dos Servidores do Incra (CNASI); Associação dos Servidores da Reforma Agrária (Assera); Associação dos Servidores do Incra (Assincra).

${ }^{10}$ Além disso, o governo havia prometido contratar 137 servidores para o Incra e abrir concurso para 1.300 vagas no órgão. A reivindicação do MST era, no entanto, de 4 mil novos funcionários para poder reestruturar e fortalecer o Incra: "Ambicionávamos mais, mas foi o possível construir e saímos satisfeitos do entendimento com 
vindicações permitiam que, por meio do engrandecimento da legitimidade e da urgência de uma reforma agrária, fossem atendidas tanto as demandas dos funcionários de carreira do Instituto como as dos próprios movimentos ${ }^{11}$.

Os primeiros concursos para o Incra foram realizados no ano de $2004^{12}$ como resultado direto dessas pressões, mas, na avaliação tanto de sindicalistas como dos movimentos, elas são ainda insuficientes. Isso fica demonstrado pela pauta do "Grito da Terra Brasil de 2014", que trazia, entre diversas reivindicações:

Estruturar e fortalecer o Incra, realizando concurso público para a contratação imediata de servidores em número suficiente para atendimento das demandas e assegurar a equiparação salarial dos servidores do MDA e do Incra com os de outras áreas afins no governo federal ${ }^{13}$.

Como veremos adiante, tais alianças estratégicas não podem ser tomadas como uma regra de relação entre movimentos e servidores, seja em âmbito nacional, seja no âmbito local. O que é importante, porém, é que elas ajudam a entender as condições de permeabilidade do Estado numa situação histórica específica.

o governo", afirmou Jaime Amorim, da Direção Nacional do Movimento. Fonte: MST. Disponível em: <http://www.mst.org.br/node/578>. Acesso em: 17 nov. 2014. 11 "Em 2012, 255 pessoas se aposentaram no órgão, e a previsão é que esse número possa chegar a 2 mil até o final do governo Dilma. "A quantidade de mesas vazias em todos os setores é notória. Os que virão ajudarão a mitigar a situação, mas deve-se ter clareza que o que irá acontecer não terá condições de alterar em muito a situação de carência de força de trabalho na autarquia”. Essa declaração foi divulgada na página do MST, disponível em: <http://www.mst.org.br/Novas-vagas-no-Incra-sao-insuficientes-para-preencher-o-deficit-de-funcionarios-afirma-sindicalista>. Acesso em: 15 nov. 2014.

${ }^{12}$ Foram realizados cinco concursos para o Incra após 2003: dois em 2004, dois em 2005 e um em 2010. O total de vagas abertas nesses concursos foi de 2.216. 13 "Grito da Terra Brasil de 2014". Fonte: Contag. Disponível em: <http://www. contag.org.br/arquivos/portal/PAUTA\%20GTB\%202014sem\%20sangria.pdf>. Acesso em: 17 nov. 2014. 


\section{Definindo a assistência técnica}

Na reunião que tivemos com a direção nacional do Incra, no início de 2011, o diretor da área de assistência técnica e extensão rural estava nos explicando a nova orientação do programa, de acordo com a recém-sancionada Política Nacional de Assistência Técnica e Extensão Rural (PNATER). De acordo com o servidor de carreira, que também era filiado ao PT, o Incra estava buscando colocar em prática uma forma de substituir o sistema de convênios feitos anteriormente com entidades prestadoras de serviços de assistência técnica - muitas delas ligadas a movimentos sociais. O novo modelo de política de ATES $^{14}$ deveria ser executado por meio de contratos com essas entidades, e a direção nacional da autarquia estava empenhada em informar e treinar os servidores das Superintendências Regionais para executar a política de acordo com as novas diretrizes. Vale dizer que a PNATER foi pensada em conjunto com os movimentos sociais e demais setores envolvidos com o tema da assistência técnica (Peixoto, 2008; Lusa, 2013).

Um ano depois da aprovação da lei, foi realizada a Conferência Nacional de Assistência Técnica e Extensão Rural (CNATER), com o objetivo de orientar as diretrizes nacionais da política a partir da participação de todos os setores envolvidos. Além das etapas preparatórias, municipais e estaduais, a CNATER foi precedida por uma conferência setorial organizada pelo Incra para articular nacionalmente as diretrizes da política de assistência técnica para o público da reforma agrária. Dessa conferência setorial, que ocorreu no ano de 2012, participaram servidores das trinta Superintendências e lideranças dos principais movimentos sociais. Os servidores de Marabá que participaram da conferência setorial voltaram de

\footnotetext{
${ }^{14}$ A sigla ATES (Assessoria Técnica, Social e Ambiental à Reforma Agrária) é utilizada pelo Incra e é dirigida aos assentados da reforma agrária. E a sigla ATER (Assistência Técnica e Extensão Rural) é a sigla utilizada pelo MDA e é dirigida, de modo geral, para o público da agricultura familiar.
} 
Brasília se queixando de que teria havido, durante as reuniões, "uma dominação da pauta por parte dos movimentos sociais".

Outros acontecimentos influenciaram o processo de reestruturação da política de ATES na Superintendência de Marabá após 2011. Entre maio e junho desse ano, os três movimentos que atuam na região (Contag, Fetraf ${ }^{15}$ e MST) organizaram um grande acampamento na sede regional do Incra. Nessa ocasião, estiveram acampadas aproximadamente 5 mil famílias, dentro e em volta do prédio da SR 27. Ao longo dos 46 dias de duração do acampamento, várias reuniões foram realizadas entre superintendente, chefes de divisão e lideranças regionais dos três movimentos (CPT, 2012). Ainda sem um acordo, as lideranças exigiram a vinda do presidente do Incra a Marabá - reivindicação sustentada pela demonstração da capacidade de organização massiva e de longo prazo.

Com a presença do presidente nacional do Incra em Marabá, uma série de acordos foram feitos ${ }^{16}$. Estabeleceram76 -se metas para a desapropriação de áreas, assentamento de famílias, distribuição de créditos, construção de casas e assistência técnica. O cumprimento desses acordos exigia aumento no orçamento destinado à região e, por isso, a presidência do Incra articulou uma reunião das lideranças locais com o ministro do Desenvolvimento Agrário. Nessa reunião, as lideranças conseguiram garantir um compromisso, por parte do ministro, o que resultou no aumento significativo dos recursos a serem destinados para a Superintendência naquele ano: o orçamento inicial de 8 milhões fora ampliado para 40 milhões.

Boa parte desses recursos deveriam ser destinados à execução da política de assistência técnica mediante estabelecimento de contratos com entidades prestadoras do serviço. Em uma segunda reunião na sede do Incra em

\footnotetext{
${ }^{15}$ Federação dos Trabalhadores na Agricultura Familiar.

${ }_{16}$ Para maiores informações sobre as demandas dos movimentos, ver a "Carta à População de Marabá”, redigida pelos três movimentos sociais após quarenta dias de ocupação e reproduzida no relatório da CPT de 2011 (CPT, 2012).
} 
Brasília, em setembro de 2011, o servidor responsável pela coordenação nacional da política de ATES, filiado ao PT e ex-superintendente da SR 11 (Rio Grande do Sul), nos explicou que seu setor estava atualmente trabalhando com um plano prioritário para a SR 27. De acordo com ele, "os movimentos tinham conseguido", após a grande mobilização de junho, um acordo com o ministro, que garantia a universalização da política de ATES na região. Universalização da política significava a garantia de que todas as famílias assentadas na área da SR 27 teriam acesso à assistência técnica. O servidor explicou que o cumprimento dessa ação, negociada com os movimentos, exigia um esforço conjunto por parte de Brasília e da Superintendência Regional ${ }^{17}$.

Como o compromisso com os movimentos tinha sido ainda para o ano de 2011, eles estavam correndo para garantir a contratação das entidades o mais rápido possível. Com esse objetivo, sua equipe estava trabalhando com a equipe local há alguns meses e ele iria pessoalmente a Marabá, em outubro, para participar de uma reunião de esclarecimento sobre a nova política de ATES.

O responsável pela organização dessa reunião, da qual participaram todos os servidores da SR 27 e das Unidades Avançadas - evento praticamente inédito no Incra de Marabá -, era um militante do PT de longa data e um dos fundadores do partido no sudeste do Pará. Em outubro de 2011, ele ocupava o cargo de chefe de gabinete da Superintendência e tinha importante função de articulador político e assessor do superintendente - um ex-militante do MST e também filiado ao PT. A articulação e organização do evento com a participação do chefe do setor de ATES vindo de Brasília implicava mais do que a conexão hierárquica e

\footnotetext{
${ }^{17}$ A contratação das entidades prestadoras de ATES é feita por chamada pública, que deve conter os critérios e metas definidos pelo Incra para a prestação do serviço. Cada região tem uma chamada pública diferente, de acordo com as especificidades e necessidades locais.
} 
burocrática do Incra. Os dois servidores também estavam conectados pelo partido em que militavam, embora pertencentes a diferentes tendências internas do PT. Vale lembrar que o partido também conecta as lideranças dos movimentos que criam e organizam a demanda de beneficiários do Incra (Vergara-Camus, 2009; Penna, 2013).

Essa reunião, na qual um dos pesquisadores esteve presente, foi marcada por uma série de questionamentos por parte dos servidores a respeito da capacidade operacional da Superintendência para a execução de uma política com essa escala. Existiam aproximadamente 60 mil famílias assentadas na área sob responsabilidade da regional, que contava então com cerca de 200 servidores apenas. Muitos desses assentamentos são longe da sede e de difícil acesso, e a reticência por parte dos servidores em relação às condições operacionais para a implementação e fiscalização dos contratos se fez presente na forma de questionamentos ao 78 longo de toda a reunião.

As respostas do gestor de Brasília, do superintendente regional, do chefe de gabinete, e da equipe local responsável pela execução da política foram uníssonas ao utilizarem o mesmo argumento: "os acordos já tinham sido estabelecidos em um nível mais alto e agora só cabia à Superintendência executar as metas definidas em Brasília”. Eles faziam referência às negociações entre movimentos, presidência do Incra e ministro, que culminaram na liberação de orçamento e no compromisso, por parte do Estado, do cumprimento das metas definidas com os movimentos. Neste caso específico, a interação entre burocratas de alto e médio escalão e representantes do público beneficiário da reforma agrária (lideranças também de alto e médio escalão na estrutura organizacional dos movimentos) teve impacto sobre o trabalho dos servidores de baixo escalão que trabalhavam na Superintendência e nas Unidades Avançadas. Não podemos esquecer, no entanto, que os acordos firma- 
dos em Brasília surgiram das pressões feitas pelo movimento sobre os funcionários daquela Superintendência no acampamento de 2011 e nas visitas de campo aos assentamentos e acampamentos.

Em que pese a interação cotidiana dos servidores do Incra com lideranças de movimentos sociais, do baixo ao alto escalão, eles nem sempre têm percepções homogêneas e inequívocas quanto a esses representantes do público beneficiário, ou quanto ao papel dos próprios movimentos. Meses após o acampamento de junho de 2011, um dos pesquisadores conversou com alguns servidores sobre como eles avaliavam aquela mobilização. Alguns a viam como positiva, uma vez que tinha contribuído para aumentar o orçamento do órgão; e outros viam-na como negativa, pois emperrava e atrasava o trabalho do Incra, haja vista que, durante toda a ocupação, a SR ficara fechada e tudo estava parado. Outros servidores não se conformavam com o fato de os movimentos atropelarem a agenda e a programação da Superintendência, fazendo os servidores trabalharem sob pressão para o cumprimento de metas que haviam sido negociadas de cima para baixo - muitas das quais impossíveis de serem cumpridas. Todavia, o importante papel dos movimentos de pressionar o Estado por políticas públicas de reforma agrária e de fazer a representação dos beneficiários também é reconhecido pelos servidores. A maioria das pessoas leva em consideração vários desses pontos em suas análises, que, portanto, não podem ser enquadradas simplesmente como favoráveis ou contrárias à atuação dos movimentos.

A interação que ocorre em múltiplos níveis entre Incra e movimentos sociais é denominada "relação de parceria" por ambos, como afirmamos antes. Essa relação de parceria se dá tanto no momento da negociação de metas e prioridades, o que geralmente ocorre por intermédio da interação entre a burocracia de alto e médio escalão e as lideranças 
também de alto e médio escalão. Vale dizer que essa interação é normalmente precedida por mobilizações massivas, diretamente proporcionais ao poder de barganha que os movimentos podem levar à negociação. No nível de rua, a relação de parceria envolve a cooperação dos movimentos no momento de execução das políticas. Eles têm o papel, prático, de organizar e apresentar ao Incra famílias beneficiárias do Programa Nacional de Reforma Agrária (PNRA), e de indicar áreas a serem obtidas para fins da reforma agrária. Esse processo se dá com a interação cotidiana entre servidores e lideranças de baixo escalão. A "parceria" nesse nível nem sempre ocorre de forma consensual e pacífica. Os papéis de cada ator estão constantemente em disputa, uma vez que tanto lideranças como servidores almejam obter maior controle sobre o processo. Seria mais adequado dizer que ela se concretiza na acomodação e negociação de uma série de temas controversos que sobrepõem Estado 80 e movimentos sociais em diferentes níveis.

****

$\mathrm{O}$ que as pesquisas que realizamos nas últimas décadas demonstram é que essa malha complexa, que conhecemos por reforma agrária, não se estrutura apenas em Brasília, na sede nacional do Incra, e nem que a sede seja o único local onde ocorrem as chamadas parcerias com movimentos. Ao longo do artigo, procuramos demonstrar que, no caso do Incra, a interação entre Estado e movimentos que produzem o público do PNRA se dá em múltiplos níveis, que vão desde o nível de rua (Lipsky, 1980), ao mais alto escalão, em Brasília. Nossos dados apontam que, tanto na literatura que olha para a interação entre Estado e movimentos, quanto na literatura que olha para a relação entre burocratas e clientes, haveria uma desatenção para fato de que não estamos tratando de um Estado pronto, definido 
e homogêneo. Nossa premissa metodológica é que ele não deve ser visto dessa forma em nenhum lugar, uma vez que as políticas que produzem são, em diversos contextos, agenciadas com mediadores internos e externos ao seu heterogêneo corpo de funcionários (Penna, 2013).

Para usar metáfora de Lipsky (1980), poderíamos argumentar que há várias ruas que cruzam o Incra ou ainda que as portas do Estado não estão abertas apenas no momento da implementação de uma política. Pela natureza do órgão e de suas políticas, o trabalho cotidiano de burocratas de alto, médio e baixo escalão é realizado em contato frequente com as lideranças desses movimentos - que também se organizam em diferentes níveis e com diversos objetivos. Tais contatos ou mediações, como preferimos usar ao longo do texto, criam efeitos horizontais e verticais e nem sempre de cima para baixo. Se, como vimos, no caso da política de assistência técnica, os acordos para sua implementação haviam sido tomados em um "nível mais alto" (nível no qual os movimentos também influenciam), não podemos esquecer que essa decisão partiu de pressões sobre a própria Superintendência realizadas por movimentos locais durante sua longa ocupação. O mesmo pode ser dito das ocupações da sede do Incra que cobraram aumento de orçamento e concursos públicos nacionais para o órgão e que resultaram de pressões sofridas pelos próprios servidores em suas visitas de campo a assentamentos e acampamentos.

Assim, as conexões aqui descritas alteram o próprio tamanho e a forma do Estado que não apresenta contornos definitivos, contribuindo para uma constante fluidez no trabalho de seus servidores.

Também é preciso destacar que a absorção, por meio de concursos públicos e não por indicações políticas, de militantes do PT e de pessoas ligadas aos movimentos sociais rurais, aumentam a permeabilidade do órgão a demandas externas. 
Retomando as hipóteses apresentadas no começo deste artigo, gostaríamos de concluir afirmando que os casos em questão demonstram que a relação entre movimentos, Estado, partidos, servidores e beneficiários individuais pode ser observada tanto na formulação como na distribuição e circulação das políticas de reforma agrária. Sem que precisemos olhar apenas para o Estado ou para os movimentos como polos analíticos homogêneos, sugerimos que seja útil analisar a reforma agrária como um ator-rede, ou seja, como um produto de efeitos gerados por diversos actantes com capacidade de agência e mesmo com magnitudes diferentes (Latour, 2005).

Evitar os esquemas teóricos dualistas e suas tendências à homogeneidade, nos deixaria como alternativa de análise não a fonte da ação, mas seu principal efeito, que são as próprias políticas de reforma agrária.

Para concluir, lembramos ainda que tanto para servidores, quanto para movimentos e beneficiários, o Incra ainda 82 se encontra longe de cumprir suas expectativas. Analisar isso, no entanto, foge ao escopo deste de artigo, pois exigiria incorporar novos actantes e suas agências, que produzem, circunstancialmente, também efeitos sobre as políticas que circulam por esse local.

\section{Camila Penna}

é doutora em Sociologia e pesquisadora da Universidade de Brasília (UnB).

\section{Marcelo C. Rosa}

é professor da UnB e pesquisador do CNPq.

\section{Bibliografia}

ABERS, R.; KECK, M. 2006. "Civil society and State building in Latin America”. Debates LASA Forum, v. 37, n. 1, pp. 30-32.

ABERS, R.; SERAFIM, L.; TATAGIBA, L. 2014. "A participação na era

Lula: repertórios de interação em um Estado heterogêneo”. Dados, v. 57, n. 2, pp. 235-357. 
ABERS, R.; VON BULOW, M. 2011. "Movimentos sociais na teoria e na prática: como estudar o ativismo através da fronteira entre Estado e sociedade?”. Sociologias, Porto Alegre, ano 13, n. 28, pp. 52-84.

BORGES, A. 2005 (2006). "O emprego na política e suas implicações teóricas para uma antropologia da política”. Anuário Antropológico 2005 (2006), pp. 91-125.

CARTER, M. 2010. Combatendo a desigualdade social: o MST e a reforma agrária no Brasil. São Paulo: Ed. Unesp.

CPT - Comissão Pastoral da Terra. Conflitos no campo - Brasil 2011. 2012. (Orgs.: Antônio Canuto, Cássia Regina da Silva Luz, Isolete Wichinieski). Goiânia: CPT Nacional Brasil.

DEERE, C. D. 2003. "Women's land rights and rural social movements in the Brazilian agrarian reform”. Journal of Agrarian Change, v. 3, n. 12, pp. 257-88.

DUBOIS, V. 2010 (1999). The bureaucrat and the poor: encounters in French welfare offices. Burlington: Ashgate.

GOLDSTONE, J. 2003. Introduction: "Bridging institutionalized and non institutionalized politics". In: States, parties and social movement. Davis: University of California.

LATOUR, B. 2005. Reassembling the social: an introduction to actor-networktheory. Oxford: Oxford University Press.

LAW, J. 2004. After method: mess in social science research. New York: Routledge.

LIPSKY, M. 1980. Street-level bureaucracy. Dilemmas of the individual in the public service. New York: Russel Sage Foundation.

LOPEZ, F. G.; BUGARIN, K.; BUGARIN, M. 2013. "Partidos, facções e a ocupação de cargos de confiança no Executivo federal (1999-2011)". In: $37^{\circ}$ ENCONTRO ANUAL DA ANPOCS. GT 3 Estudos legislativos: avanços e perspectivas. Caxambu: Anpocs.

LOTTA, G. S. 2010. Implementação de políticas públicas: o impacto dos fatores relacionais e organizacionais sobre a atuação dos burocratas de nível de rua no Programa Saúde da Família. Tese de doutorado em Ciência Política. São Paulo: USP.

LUSA, M. G. et al. 2013. "Política Nacional de Assistência Técnica e Extensão Rural e serviço social: o campo como desafio”. Cadernos $C E R U$, v. 24, n. 1, pp. 115-135.

MARTINS, J. S. 2000. “As mudanças nas relações entre a sociedade e o Estado e a tendência à anomia nos movimentos sociais e nas organizações populares”. Estudos Avançados, v. 14, n. 38, pp. 268-78.

MAYNARD-MOODY, S.; MUSHENO, M. 2003. Cops, teachers, counselors: stories from the front lines of public service. Ann Arbor: The University of Michigan Press. 
MELLO, P. F. 2012. "Reforma agrária brasileira: uma análise da brokerage". Estudos Sociedade e Agricultura, v. 20, n. 2, pp. 430-50.

MISCHE, A. 2008. Partisan publics: communication and contention across Brazilian youth activist networks. Princeton: Princeton University Press.

MOYO, S.; YEROS, P. 2005. "The resurgence of rural movements under neoliberalism”. In: MOYO, S.; YEROS, P. (eds.). Reclaiming the land: the resurgence of rural movements in Africa, Asia and Latin America. London: Zed Books.

OLIVEIRA, A. 2012. "Burocratas na linha de frente: executores e fazedores das políticas públicas”. Revista de Administração Pública - RAP, v. 43 , n. 6 , pp. 1551-73.

PEIXOTO, M. 2008. Extensão rural no Brasil: uma abordagem histórica da legislação. Brasília: Senado Federal (Consultoria Legislativa).

PENNA, C. 2013. Conexões e controvérsias no Incra de Marabá: o Estado como um ator heterogêneo. Tese de doutorado em Sociologia. Brasília: UnB.

PIRES, R. 2009. "Burocracia, discricionariedade e democracia: alternativas para o dilema entre controle do poder administrativo e capacidade de implementação”. Cadernos Gestão Pública e Cidadania, n. 14, pp. 141-80.

PRAÇA, S.; FREITAS, A.; HOEPERS, B. 2011. "Political appointments and coalition management in Brazil, 2007-2010". Journal of Politics in Latin America, v. 3, n. 2, pp. 141-72.

ROSA, M. 2011. O engenho dos movimentos: reforma agrária e significação social na zona canavieira de Pernambuco. Rio de Janeiro: Garamond.

SABOURIN, E. 2008. "Reforma agrária no Brasil: considerações sobre os debates atuais”. Estudos Sociedade e Agricultura, v. 16, n. 2, pp. 151-184.

SIGAUD, L. 2005. "As condições de possibilidade das ocupações de terra. Tempo Social, v. 17, n. 1, pp. 255-80.

SIGAUD, L.; MACEDO, M. E.; ROSA, M. C. 2010. Ocupações e acampamentos: sociogênese das mobilizações por reforma agrária no Brasil (Rio de Janeiro, Rio Grande do Sul e Pernambuco) 1960-2000. Rio de Janeiro: Garamond.

SILVA, M. K.; OLIVEIRA, G. L. 2011. "A face oculta(da) dos movimentos sociais: trânsito institucional e intersecção Estado-movimento - uma análise do movimento de economia solidária no Rio Grande do Sul”. Sociologias, Porto Alegre, ano 13, n. 28, pp. 86-124.

SOUZA, C. H. L.; PIRES, R. 2013. "Conferências nacionais como interfaces socioestatais: seus usos e papéis na perspectiva de gestores federais”. In: AVRITZER, L.; SOUZA, C. (orgs.). Conferências nacionais: atores, dinâmicas participativas e efetividade. v. 1. Brasília: Ipea.

TILLY, C. 2006. Regimes and repertoires. Chicago: University of Chicago Press. 
VERGARA-CAMUS, L. 2009. "The politics of the MST: autonomous rural communities, the State and electoral politics". Latin American Perspectives, v. 36, n. 4, pp. 178-91.

VON BÜLOW, M. 2013. "The politics of scale shift and coalition building: the case of the Brazilian network for the integration of the peoples". In: SILVA, E. (org.). Transnational activism and national movements in Latin America: bridging the divide. New York: Routledge.

WOLFORD, W. 2010. "Participatory democracy by default: land reform, social movements and the State in Brazil". The Journal of Peasant Studies, v. 37, n. 1, pp. 91-109. 


\section{ESTADO, MOVIMENTOS E REFORMA AGRÁRIA NO BRASIL: REFLEXÕES A PARTIR DO INCRA}

CAMILA PENNA

MARCELO C. ROSA

Resumo: Neste artigo, procuramos analisar um dos actantes centrais nos processos de reivindicação por terras no Brasil contemporâneo: o Instituto Nacional de Colonização e Reforma Agrária (Incra). Debatendo com a literatura que analisa as relações entre Estado e movimentos sociais por meio da constituição de políticas públicas, trazemos dois estudos de caso realizados no Incra, nos estados do Pará e de Pernambuco, na última década. Em ambos, a relação entre Estado e movimentos altera a forma e o tamanho do Instituto, transformando as funções e rotinas de seus servidores. Nossa principal conclusão é de que a heterogeneidade das conexões que formam o Incra tornam o Estado permeável simultaneamente na produção, distribuição e aplicação das políticas de reforma agrária, reforçando simultaneamente o papel do Estado e dos movimentos sociais nesse processo. Palavras-chave: Movimentos Sociais; Estado; Políticas Públicas; Incra; Reforma Agrária.

\section{STATE, MOVEMENTS AND AGRARIAN REFORM IN BRAZIL:" REFLEXIONS FROMI THE INCRA}

Abstract: In this paper we seek to analyse one of the major actants in the agrarian reform process in Brazil: the National Institute for Colonization and Agrarian Reform (Incra). In order to challenge the current literature on the formulation of policies through the state/movements relations we bring to case studies carried out in the states of Pernambuco and Pará after 2000 embracing bureaucrats, managers, activists and beneficiaries in a network of actions. We conclude that the heterogeneity of the Institute and state as whole 
contributes for a new understanding of Incra as not only the executor of the agrarian reform, but as an active producer of its contemporary meanings in the country.

Keywords: Social Movements; Agrarian Reform; Land Reform; State; Policies; INCRA.

Recebido: 06/12/2014 Aprovado: 08/05/2015 